\title{
Scientific and Technological Creativity and Entrepreneurship in The Process of Projecting in Collaborative Graduation Qualification Works
}

\author{
Guzel Gazimovna Sunaeva ${ }^{*}$, Svetlana Gazimovna Sunaeva $^{2}$, Oksana Sergeevna Goltseva $^{2}$, \\ Tatiana Evgenievna Belyakova ${ }^{2}$, and Konstantin Nikolaevich Shevalie ${ }^{2}$ \\ ${ }^{1}$ Ufa State Petroleum Technological University, Department of Project Management and Business \\ Economics, Ufa, Russia \\ ${ }^{2}$ K.G. Razumovsky Moscow State University of technologies and management (the First Cossack \\ University), Department of Design and Applied Arts, Moscow, Russia
}

\begin{abstract}
The aim of the study is the introduction of elements of entrepreneurial creativity into the university learning process to form a project team, which consists of students from different areas of specialization. The method of a business game is used, when students, preparing the collaborative graduation qualification work, find themselves in a modulator of real contradictory relations between the specialists of an enterprise: technologists, designers, managers and economists. The development of the project business model according to the method of A. Osterwalder recreates the professional situation of the comprehensive solution of production problems at an enterprise. The results of the study show an increase in the synergy of scientific, technological and entrepreneurial creativity of students. As a result of project education at university, students demonstrate the acquired soft skills, which ensure successful participation in the work process and high productivity; they experience the excitement and show higher results of their collaborative graduation qualification work. Graduation qualification work acquires the features of a startup and has higher characteristics for introducing goods and services in the market. The presentation of the collaborative graduation qualification work reproduces the real situation of the evaluation of innovative idea prospects, an idea development plan and a team of likeminded people. The experience of participating in the business model development after the request of partners of an entrepreneurial university increases the competitiveness of graduates in the labour market.
\end{abstract}

\section{Introduction}

Graduation qualification work can be prepared cooperatively by several students, including students from different areas of specialization, in the form of a collaborative graduation qualification work. Students find themselves in a contradictory life situation, which requires

\footnotetext{
* Corresponding author: sunaeva.guzel@gmail.com
} 
not only professional competences, but also perseverance, communicability, emotional stability, independence, the ability to take and delegate responsibility.

The universities have developed a technique for working on projects [1]. Educational courses on entrepreneurship [2-4] and project management [5-7] are actively introduced in the university curricula. At the same time, students before graduation are mostly in a professionally homogeneous environment, without knowing enough about interdisciplinary problems. Thus, as for students from the faculty of light industry and specialization area of wearing apparel design, they choose materials, models of clothes and accessories or develop new models, designs of knots and design drawings of parts, make prototypes of products or collections of models. As for students from the faculty of design and specialization area of environmental design, the project is interior design, urban environmental design, eventdesign, etc. Students from specialization area of graphics design project corporate style and designs of printing, environmental objects in an urban environment, navigation systems and social networks. Students from the faculty of economics and management study project management and business valuation, conduct market research, write business plans, justify the export of goods, etc.

The experience of interaction between students from different departments, in which future economists and managers studied the workwear market, and students of the personnel management faculty conducted a preliminary study of the requirements of workwear users through questionnaires [8], showed how difficult it is to organize the cooperation of students from different areas of specialization.

Therefore, the coordination of a group of students from different areas of specialization remains a problem in preparing the collaborative graduation qualification work. A group of students needs to become a team of like-minded people while working on a project, to be able to understand each other's professional approaches. The experience of participating in the collaborative graduation qualification work managing shows that an additional means of team building is needed. To form a project team, we suggest using the development of a business model by A. Osterwalder [9], which is known for developing the Business Model Canvas system for analyzing business models for entrepreneurs. The development of a business model for a project is a less time-consuming process and precedes the development of a business plan of a project. The multifaceted discussion of the whole complex of elements in their interconnection and interaction by the project team is very important in the development of the business model of the project. The revision of the business model is faster when problems arise. This means of project management will allow the team of the collaborative graduation qualification work to discuss the main elements of the idea in their interaction with each other and to identify weaknesses during the early stages of work. In addition to the implementation schedule of the graduation qualification work, it will be useful to use the project implementation schedule.

\section{Methods}

For students, it is important to understand while working on a project, how developments can be successfully commercialized. A direct connection was found between creativity and entrepreneurial intentions [10] but learning the basics of entrepreneurship in universities becomes necessary [11-14].

The most difficult act of an entrepreneur when creating a business is to identify customers. On the first stage of planning, hypotheses are built on how the product solves the problems of potential customers. The entrepreneur needs to prove that the product has competitive advantages over existing ones in the market in real conditions of supply and demand. Description of the customers and their problems is the main task of marketing. This stage aims to select a small but homogeneous segment, basing on the Pareto principle, according 
to which $80 \%$ of revenue comes from $20 \%$ of customers. The entrepreneur's ability to focus on a market segment allows identifying their competitive advantages and strategizing sales.

The nine elements of the business model are classified into four blocks: "Customers", "Value Propositions", "Infrastructure" and "Finances". The block "Customers" include three elements of the business model: customer segment, customer relationships and channels. It is important to choose the most likely customers and a stable segment of the market share at the stage of identifying. The intention to solve the customers' problems sets up the sales channel and determines the revenue stream (the element from the "Finances" block). The customer's readiness to pay for the good builds up the business process. This chain of links should be central in the actions of the project team, as the customer's problem can be solved in several ways that the project Proposition competes with. The project Proposition should prove its value to the customer: what problem do we help to solve? What need do we satisfy? Values can be both qualitative (design, ergonomic design, customer experience, status), and quantitative (price, speed of service). At the stage of customer verification (searching for early followers), the customer hypothesis may turn out to be incorrect and it will be necessary to return to the first stage. That is why the "Customers" block must be carefully designed, and all participants of the collaborative graduation qualification work must create a portrait of the customer and discuss it from their professional point of view.

The second block of the business model also needs to be carefully designed by the entire project team and its niche in the market needs to be determined. The project Proposition should be shown in comparison with others to understand the advantages and disadvantages that the customer will compare. This is a question of demonstrating the level of qualification of a graduate and it is the most understandable one for students. At the same time, they consider this issue from different professional points of view, and their coordination plays a decisive role.

The third block of the business model combines the key processes and resources of the main activity, including key partners, and is associated with the element of the business model called "Infrastructure". Students learn to take into account that the necessary resources may be unavailable or expensive; that they must be evaluated, combined, properly attracted, etc. The need for cooperation with partners outside the project team draws their attention to taking into account the interests of other professionals, as well as the strengths and weaknesses of negotiating positions.

The fourth block of the business model balances costs and revenues. Students should be prepared for multiple budget changes: preliminary estimate, final estimate, etc. Excessive detailing only distracts at the beginning of the work on the project. It is important to focus on the main resources: the most expensive, rare and limited ones. A key partner is a provider of significant resources, its main activities and the motivation for creating partnerships are thought over.

It is useful to prepare a presentation of the project business model at the beginning of the collaborative preparation of the graduation qualification work to achieve accurate formulations of the project concept. This presentation should be identified as the first control point of teamwork and should be discussed with professors to get an initial evaluation of the idea. The project coordinator and students supervisors will be able to understand whether a team of like-minded people has established and whether they have developed a plan of actions. The main period for the preparation of the graduation qualification work is devoted to the student's independent work. The necessary self-educational competence of the student is formed during professional education [15].

The second control point of teamwork is the development of a work breakdown structure of a project. There is a general picture formalization of the project's final product. What is the final product and what need does it satisfy? In what elements is it divided and how do these elements work in one system? At the lower level of decomposition, work packages are 
depicted. They are a unit of project activity measure; they have deadlines, costs and quality requirements; they are guaranteed by particular individuals. Under the work breakdown structure, the project team create an implementation schedule of the project work and a responsibility matrix, and control points of the project work are pointed. The second presentation of the team of the collaborative graduation qualification work is advisable after the preparation based on the work breakdown structure of the implementation schedule and the responsibility matrix.

The reason for the decomposition of the project can be the product structure (functional or elemental), the structure of the project management processes, the structure of the project management functions, the organization structure, the structure of the project life cycle. In most cases, several reasons are used for structuring.

As a result of the decomposition, an illustrative graphic and a compact textual representation of the project content will be obtained ("a goal tree"). The work breakdown structure includes all the works performed by all project participants and interested individuals [16].

\section{Results}

Using a business model as a means of project management enhances the self-organization of the students included in the preparation of the collaborative graduation qualification work. Graduates' soft skills are activated in the project activities, they are aimed at achieving results. The results of the project are based on the fact that students can collaborate, think and solve problems systematically, manage emotions and ask questions.

\section{Discussion}

Those who request the collaborative graduation qualification work are industrial partners of universities. The entrepreneurs engage students from different areas of specialisation and each of them carries out a part of project work in collaboration with the others. The terms of reference of the project should contain the requirements of the requisitioner for each aspect of the project. To show the skill of collecting information and work with it in the process of communication with the requisitioner means to ask accurate questions, document information, present it clearly and understandably, and to be able to convey it to others without distortion or omission. A problem-based interview with the requisitioners is the most difficult stage of the project activity, which determines the measure of success. It is necessary to continue the research on conducting a problem-based interview with students.

\section{Conclusion}

Thus, preparing the collaborative graduation qualification work, students from different areas of specialisation learn to interact professionally. Graduates' soft skills should be activated by the most modern project management methods. In the future, it is necessary to develop a plan of actions for the project team, depending on the combination of the participants if the collaborative graduation qualification work. The topics of the requests from entrepreneurs should be systematized.

\section{References}

1. T. Kozhemyakina, Universitetskaya zhizn $\mathbf{1 0}$ 7-10 (2019) Available at: http://mgutm.ru/wp-content/uploads/doc/journal/university-life/10.pdf 
2. J. Kirkwood, K. Dwyer, B. Gray, The International Journal of Management Education 12(3), 307-316 (2014).

3. M. Sufian, A. Karim, Procedia Economics and Finance 35, 379-387 (2016)

4. C.G. Iwu, P.A. Opute, R. Nchu, C. Eresia-Eke, R.K. Tengeh, O. Jaiyeoba, O.A. AliyuThe International Journal of Management Education (2019)

5. M. W. Barbosa, C. de Ávila Rodrigues, The International Journal of Management Education 18(2), (2020)

6. Julia-A. Scholz, F. Sieckmann, H. Kohl, Procedia Manufacturing 45, 234-239 (2020)

7. Y.C.J. Wu, T. Wu, Y. Li, Computers in Human Behavior 92, 634-645 (2019)

8. G.G. Sunayeva, V.Sh. Karamov, A.Kh. Mutallapova. Comfortable workwear as an element of the intangible incentive system, In the collection: Relevant issues of modern science, Collection of scientific articles of the international scientific-practical conference (2018)

9. A. Osterwalder, Y. Pigneur, Business Model Generation: A Handbook for Visionaries, Game Changers, and Challengers (Alpina Pablisher, Moscow, 2019)

10. A. Laguía, J. A. Moriano, M. J. Gorgievski, Thinking Skills and Creativity 31 44-57 (2019)

11. M. Lynch, V. Kamovich, K.K. Longva, M. Steinert, Technological Forecasting and Social Change (2019)

12. A. da S. M. Ferreira, E. Loiola, S. M. Guedes Gondim, RAI Revista de Administração e Inovação 14(2), 140-150 (2017)

13. M.G. Colombo, E. Piva, Research Policy 49(6), (2020)

14. T. Ahmed, V.G.R. Chandran, J.E. Klobas, F. Liñán, P. Kokkalis, The International Journal of Management Education 18(1), (2020)

15. T.N. Efremtseva, A.R. Batyrshina, E.M. Sagilyan, S.G. Sunaeva, E.S. Petrova, Amazonia Investiga 8(20), 674-682 (2019)

16. M.L. Razu. Project management, Basics of project management: a textbook (KNORUS, Moscow, 2019) 